\title{
RELATION BETWEEN AIR POLLUTION EPISODES AND DISCOMFORT INDEX IN THE GREATER ATHENS AREA, GREECE
}

\author{
A.G. PALIATSOS ${ }^{*}$ \\ P.TH. NASTOS ${ }^{2}$
}

\author{
${ }^{1}$ General Department of Mathematics, \\ Technological Education Institute of Piraeus, \\ 250 Thivon and P. Ralli, \\ 12244 Athens, Greece \\ 2 Laboratory of Climatology, \\ Department of Geology, \\ University of Athens, \\ 15784 Athens, Greece
}

*to whom all correspondence should be addressed Accepted: 6/5/99

\section{ABSTRACT}

An attempt is made for a first general study of the relation between high/very high concentrations of nitrogen dioxide and ozone with the discomfort index (DI) values. The nitrogen dioxide data of «Patision» station and ozone data of «Liosia» and «Marousi» station have been analysed. The relation between air pollution episodes and the corresponding values of DI during the period 1993-1995 have been examined for the Greater Athens Area (GAA). For the warm period of the year, the frequency of the DI values for different levels of air pollution in the GAA is also examined.

KEYWORDS: Discomfort index; Air pollution episodes; Athens

\section{INTRODUCTION}

Athens, being a city of about $4,000,000$ inhabitants, faces as most of the other big cities in the world, air pollution problems. The rapid increase of population since 1950 , caused by the accumulation of industrial and commercial activities around the city, resulted in high pollution levels during the last 25 years. Until the mid 80's the main pollutants in the Greater Athens Area (GAA) were sulphur dioxide and smoke. Photochemical pollution followed the pollution from primary pollutants and resulted in the Athens photochemical smog. In recent years, European Union (EU) and World
Health Organisation (WHO) air quality standards are frequently exceeded in the GAA, especially concerning $\mathrm{O}_{3}$ and $\mathrm{NO}_{\mathrm{x}}$ (Mantis et al., 1992; Ziomas et al., 1995a-b, 1998a-c).

Athens is considered as a typical example of intense photochemical air pollution. In late spring and late summer the development of land/seabreeze circulation, in conjunction with the complex topography and high solar insolation favours the appearance of extreme photochemical air pollution episodes. Because of the hazardous effect of high levels of secondary air pollutants to the air 


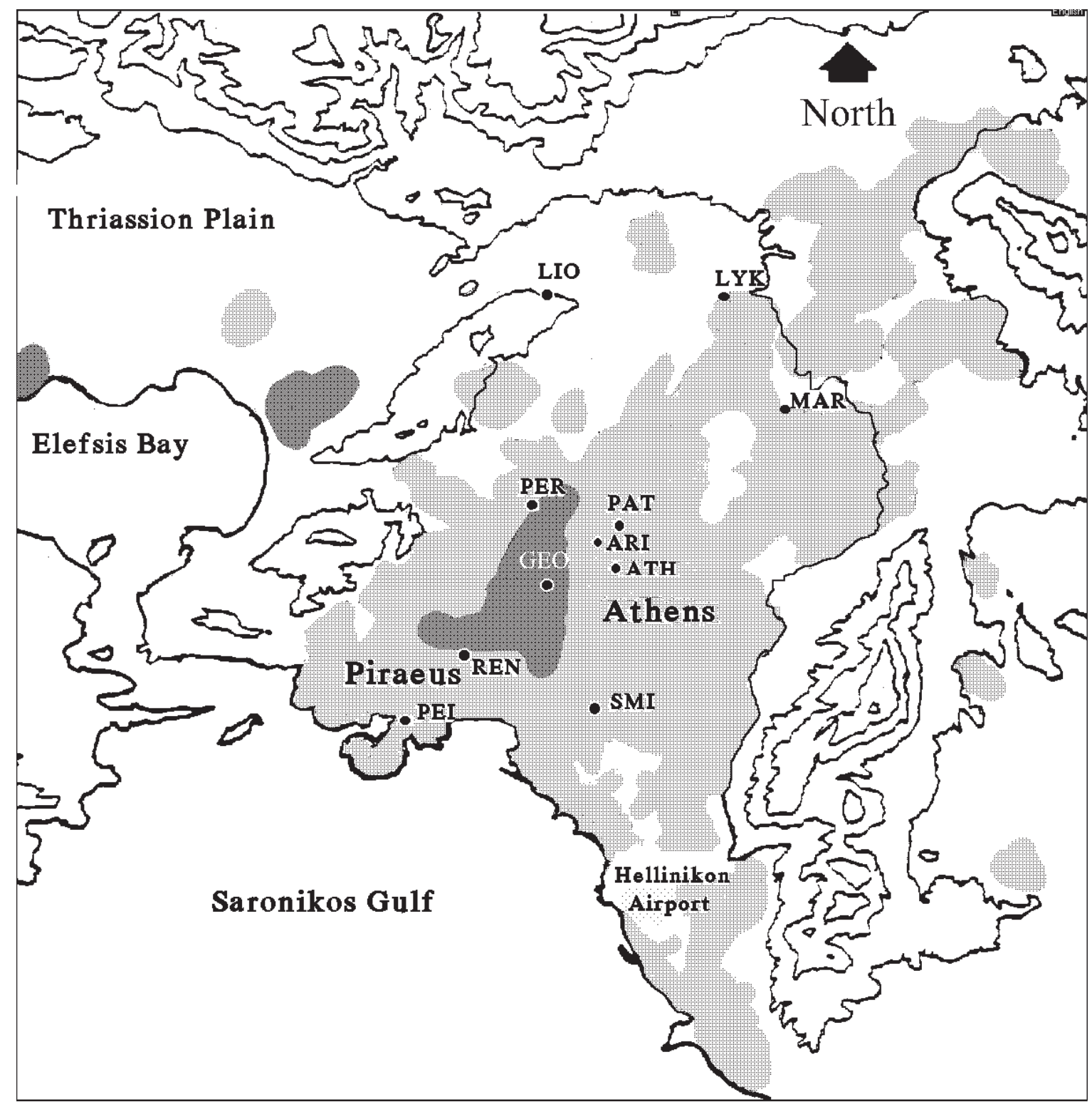

Figure 1. Map of the Greater Athens Area with elevation contours at $200 \mathrm{~m}$ intervals

quality, this is related to the health of Athens basin inhabitants (Hatzakis et al., 1986; Katsouyanni et al., 1993).

The city of Athens is located in an area of complex topography within the Athens basin $\left(\sim 450 \mathrm{~km}^{2}\right)$. The city is surrounded by mountains with heights ranging from 400 to $1500 \mathrm{~m}$ at the west, north and east sides (Fig. 1). Openings between these mountains exist at the north-east and at the west of the basin, while at the south there is the sea (Saronikos Gulf). The Athens basin has a south-west to north-east major axis and is bisected by a series of small hills. Most of the industrial activities emitting sulphur dioxide contaminants are located to the south-west of the basin, near the Piraeus harbour, consisting of textile, cement, chemical, fertiliser, paint and paper factories. Other sources of sulphur dioxide pollution are the ships in Piraeus harbour, at the southwest edge of the basin, and the airplanes at the Athens International Airport (Hellenikon), at the south-east edge. Moreover, outside the Athens basin and to the west side of the city lies a big industrial area, with refineries, steel works, 
cement plants and shipyards, emitting sulphur dioxide contaminants.

The climate of Athens is Mediterranean with wet, mild winters and hot, dry summers. The mean daily temperature is $10^{\circ} \mathrm{C}$ and $26^{\circ} \mathrm{C}$ for the winter and summer period, respectively. The Mediterranean climate is characterized by rainfall deficiency during the warm period of the year. Therefore, from the annual mean rainfall which is $390 \mathrm{~mm}$, most occurs in October and during the winter months. The average daily sunshine duration varies between 4.5 hours in January and 12 hours in July. The prevailing winds in the Athens basin blow from $\mathrm{N}$ and NE in late summer, fall and winter, and from SSW and SW in the spring and early summer. These NE and SW directions coincide with the major geographical axis of the basin. The ventilation of the basin is poor during the prevalence of local circulation systems, such as sea/land-breezes along the major NE-SW geographical axis of the basin. The vertical temperature gradient is measured at the Hellinikon Airport headquarters of the Greek Meteorological Service twice a day at 00:00 and 12:00 GMT. Various researchers determined the characteristics of inversions and the influence of various meteorological parameters on air pollution episodes (Tselepidaki et al., 1983, 1988; Katsoulis et al., 1988).

In the summer of 1983 a network was established by the Ministry of the Environment, Physical Planning and Public Works (MEPPPW) to measure, by automatic stations, $\mathrm{CO}, \mathrm{NO}, \mathrm{NO}_{2}, \mathrm{SO}_{2}$ and $\mathrm{O}_{3}$ concentrations. The data for the nitrogen dioxide and ozone concentrations obtained by the MEPPPW network has been analysed by various researchers in the past (Lalas et al., 1987; Gusten et

Table 1. Classification of the DI values (Giles et al., 1990) al., 1988; Mantis et al., 1992; Moussiopoulos et al., 1993; Ziomas et al., 1995b-c, 1998a-b).

Until now according to the scientific literature, the air pollution problem in Athens has not been examined by means of appropriate air quality indices, although such approaches have been applied elsewhere (Boubel et al., 1994). In the current work an attempt is made to study the relation between high/very high concentrations of nitrogen dioxide and ozone with the discomfort index (DI) values.

\section{METHOD}

In the present work, the discomfort index (DI) (Thom, 1959) has been used to account for possible adverse health effects on the GAA's inhabitants resulting from unfavourable bioclimatic conditions, during days with air pollution episodes. In estimating DI in degrees Celsius the following equation by Giles et al. (1990) has been applied:

$$
\mathrm{DI}=\mathrm{T}_{\mathrm{a}}-0.55(1-0.01 \mathrm{RH})\left(\mathrm{T}_{\mathrm{a}}-14.5\right)
$$

where $T_{a}$ is the hourly value of the mean air temperature in degrees Celsius and RH is the corresponding hourly value of the relative humidity as a percentage. Discomfort increases as DI increases.

The data of hourly values of mean air temperature and relative humidity for the computation of DI hourly values for the years 1993 to 1995 have been obtained from the records of the Institute of Meteorology and Physics of the Atmospheric Environment (IMPAE) of the National Observatory of Athens (NOA) $\left(\lambda=23^{0} 43^{\prime} \mathrm{E}\right.$, $\left.\varphi=37^{0} 58^{\prime} \mathrm{N}, \mathrm{h}=107 \mathrm{~m}\right)$.

\section{RESULTS AND DISCUSSION}

Mean daily values of DI in Athens, for the years 1993 to 1995, are shown in Fig. 2. Moreover, the same figure shows the corresponding mean

\begin{tabular}{|c|l|}
\hline DI $\left({ }^{\mathbf{0}} \mathbf{C}\right)$ & Discomfort conditions \\
\hline $\mathrm{DI}<21$ & No discomfort \\
\hline $21 \leq \mathrm{DI}<24$ & Less than $50 \%$ of the total population feels discomfort \\
\hline $24 \leq \mathrm{DI}<27$ & More than $50 \%$ of the total population feels discomfort \\
\hline $27 \leq \mathrm{DI}<29$ & Most of the population suffers discomfort \\
\hline $29 \leq \mathrm{DI}<32$ & The discomfort is very strong and dangerous \\
\hline $\mathrm{DI} \geq 32$ & State of medical emergency \\
\hline
\end{tabular}


daily concentrations of nitrogen dioxide for «Patision» station (upper panel) and ozone mean daily concentrations for «Liosia» (middle panel) and «Marousi» station (lower panel).

Previous studies (Pissimanis et al., 1991;

Table 2. Relation between the DI mean daily values and the mean daily concentrations of nitrogen dioxide and ozone by using logarithmic fitting models $\mathrm{DI}=\mathrm{a}+\mathrm{b} \log \mathrm{C}$, where $\mathrm{r}^{2}$ is the variance

\begin{tabular}{|llllc|}
\hline \multicolumn{5}{c|}{ Model } \\
\hline Station & $\mathrm{r}^{2}$ & $\mathrm{a}$ & $\mathrm{b}$ & $\mathrm{C}$ \\
\hline «Patision» & 0.10 & -4.35124 & 4.24317 & {$\left[\mathrm{NO}_{2}\right]$} \\
«Liosia» & 0.52 & -18.25 & 7.63302 & {$\left[\mathrm{O}_{3}\right]$} \\
«Marousi» & 0.45 & -23.1592 & 8.6872 & {$\left[\mathrm{O}_{3}\right]$} \\
\hline
\end{tabular}

Kallos et al., 1993; Paliatsos et al., 1994; Ziomas et al., 1995b-c, 1998a) analyzed the meteorological conditions associated with high pollutant concentrations.

In order to provide a quantitative relation between the DI mean daily values and the mean daily concentrations of nitrogen dioxide and ozone, a scatter diagram was constructed. Then, the best fitting mathematical relationship was investigated and the best results were obtained with the logarithmic fitting model $(\mathrm{DI}=\mathrm{a}+\mathrm{b} \log \mathrm{C})$ and in Table 2 the results of our analysis are presented.

In Table 2 the results from examining the relation between the DI mean daily values and the mean daily concentrations of nitrogen dioxide and ozone are presented by means of a logarithmic relationship, which is the best-fit line. Also in Fig. 3 (upper, middle and lower panels) each couple of the three data sets are plotted. In all figures the solid line represents the logarithmic fitting model. From these results it appears that, for «Patision», by using the logarithmic model, only $10 \%$ of the variance $\left(\mathrm{r}^{2}=0.10\right)$ of DI values can be explained by the variations of the nitrogen dioxide concentrations. On the contrary, both for «Liosia» and «Marousi», by using the logarithmic model, $52 \%$ $\left(\mathrm{r}^{2}=0.52\right)$ and $45 \% \quad\left(\mathrm{r}^{2}=0.45\right)$, respectively, of the variance of DI values can be associated with the variations of the ozone concentrations.

The basic meteorological parameters determining the horizontal transport and dispersion of air pollutants are the mean wind speed and wind direction. In GAA, the weakening of the synoptic wind allows the development of local circulation systems, such as sea/land breezes along the axis of the basin (NE to $\mathrm{SW}$ ), which have a large impact on the dispersive state of the boundary layer. In such a case the ventilation of the basin is very poor. Ziomas et 
Figure 3. Mean daily values of DI (degrees Celsius) versus the corresponding mean daily concentrations of nitrogen dioxide for «Patision» station (upper panel) and ozone for «Liosia» (middle panel) and «Marousi» (lower panel) station, for the period 19931995. The solid line represents the logarithmic fitting model

Figure 4. Mean diurnal variation of DI during the warm period of the year (a) for the days with high level of air pollutants concentrations (heavy solid line) and (b) for all other days with medium or low level of air pollutants concentrations (solid line), for the period 1993-1995
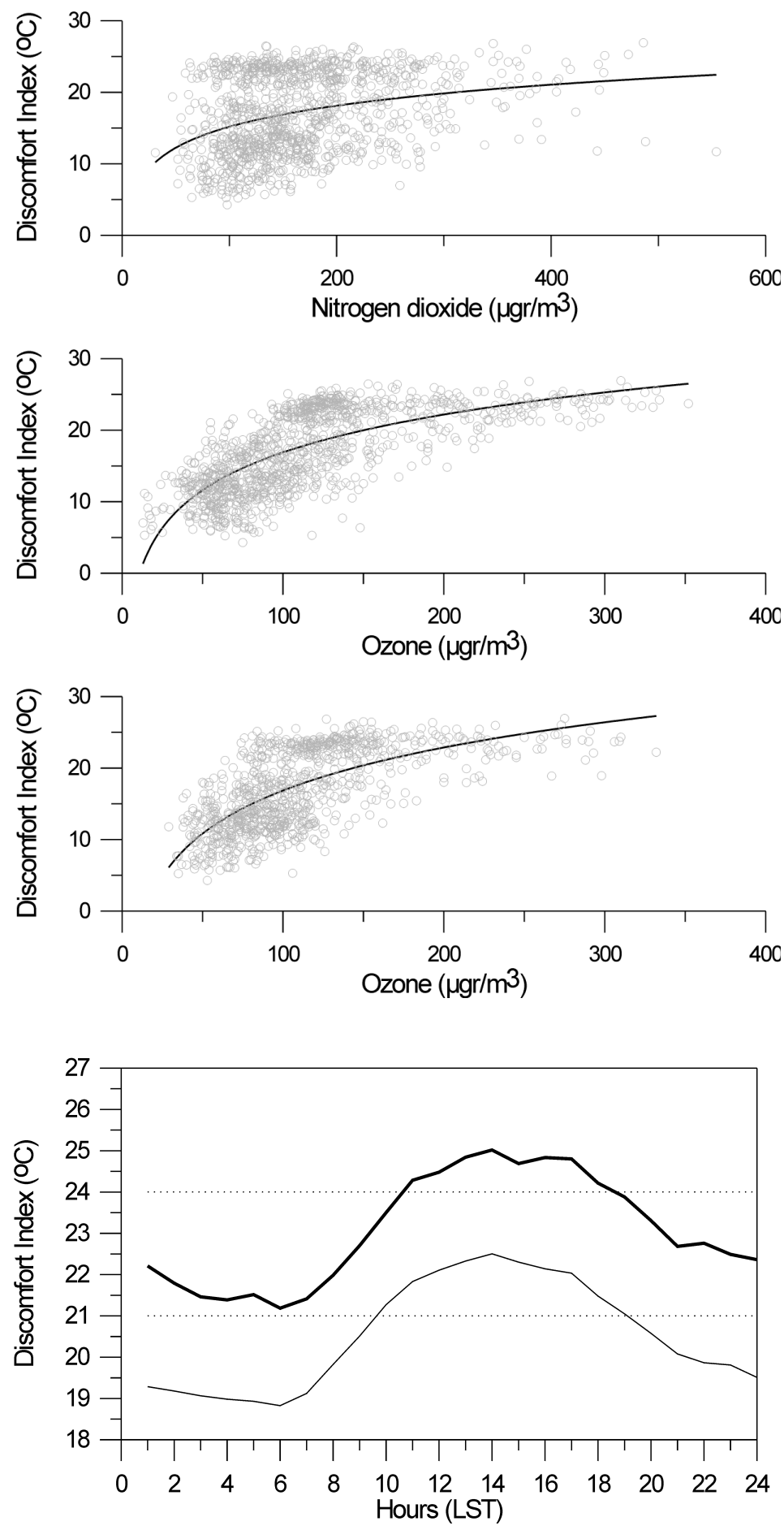

al. (1995c) have found that high ozone concentrations are observed when the wind is coming from the south-west, which is the prevailing wind direction under sea breeze condition, and high levels of solar radiation are observed. The south-west wind is in favour of a high-humidity percentage, and the intense insolation is associated with high temperatures. These meteorological conditions are related to high levels of discomfort index values.

In GAA, most of the photochemical air pollution episodes occurred during the warm period (Ziomas et al., 1995a), especially from April to 
September. During this period, the discomfort feeling of GAA's inhabitants was examined for all days for which either the maximum hourly concentration of nitrogen dioxide was greater than $350 \mu \mathrm{gr} / \mathrm{m}^{3}$, or the maximum hourly concentration of ozone was greater than $250 \mu \mathrm{gr} / \mathrm{m}^{3}$, for the years 1993 to 1995 . The mean diurnal variation of DI, for all these days (79 days), is shown in Fig. 4. The same figure shows the mean diurnal variation of DI for the other 470 days of the warm period examined.

From Fig. 4 no discomfort appears during the warm period, for all days that the observed levels of air pollution within the GAA were low or moderate, until 09:00 LST. From 09:00 to 19:00 LST, less than $50 \%$ of the total population feels discomfort, while for the rest of the day (19:00-24:00) no discomfort appears.

For the days that observed levels of air pollution were high or very high, from 00:00 to 10:00 LST, less than $50 \%$ of the total population feels discomfort, while from 10:00 to 19:00 LST, more than $50 \%$ of the total population feels discomfort. For the rest of the day (19:00-24:00), less than
$50 \%$ of the total population feels discomfort.

With regard to the DI maximum hourly values per day, during the warm period examined, it was found that only during the warm period of the year 1995 , the DI values for 16 days exceeded the $30^{\circ} \mathrm{C}$ limit, which is the limit for very strong and dangerous discomfort.

\section{CONCLUSIONS}

The DI was found to be associated with ozone concentrations and not with nitrogen dioxide concentrations. This can be attributed to the fact that the same meteorological conditions, which affect the discomfort feeling of the GAA population, cause high ozone concentrations.

The analysis of the secondary air pollutants data for the days of high or very high air pollution levels during the warm period of the year showed that more than $50 \%$ of the total GAA population feels discomfort from 10:00 to 19:00 LST.

During the warm period of the year 1995, the DI values for 16 days exceeded the $30^{\circ} \mathrm{C}$ limit, which is the limit for very strong and dangerous discomfort.

\section{REFERENCES}

Boubel, R.W., Fox, D.L., Turner, D.B. and Stern, A.C. (1994) Fundamentals of air pollution. Academic Press, New York 574.

Giles, B.D., Balafoutis, C.H. and Maheras, P. (1990) Too hot for comfort: the heatwaves in Greece in 1987 and 1988. Int. J. Biomet., 34, 98-104.

Gusten, H., Heinrich, G., Cvitas, T., Klasinc, L., Rus, B., Lalas, D.P. and Petrakis, M. (1988) Photochemical formation and transport of ozone in Athens, Greece. Atmosph. Environ., 22, 1855-1861.

Hatzakis, A., Katsouyanni, K., Kalandidi, A., Day, N. and Trichopoulos, D. (1986) Short-term effects of air pollution on mortality in Athens. Int. J. Epidemiol., 15, 73-81.

Kallos, G., Kassomenos, P. and Pielke, R.A. (1993) Synoptic and mesoscale weather conditions during air pollution episodes in Athens, Greece. Boundary-Layer Meteor., 62, 163-184.

Katsoulis, B.D. (1988) Some meteorological aspects of air pollution in Athens, Greece. Meteor. Atmosph. Phys., 39, 203-212.

Katsouyanni, K., Pantasopoulou, A., Touloumi, G., Moustris, K., Tselepidaki, I., Asimakopoulos, D., Poulopoulou, G., Trichopoulos, D. (1993) Evidence for interaction between air pollution and high temperature in the causation of excess mortality. Arch. Environ. Health, 48, 235-242.

Mantis, H.T., Repapis, C.C., Zerefos, C.S. and Ziomas, I.C. (1992) Assessment of the potential of photochemical air pollution in Athens: a comparison of emissions of air pollution levels in Athens with those in Los Angeles. J. Appl. Meteor., 31, 1467-1476.

Paliatsos, A.G. and Amanatidis, G.T. (1994) Smoke concentrations in Athens, Greece: trends and strong episodes, 1984-1991. Sci. Total Environ., 144, 137-144.

Pissimanis, D.K., Karras, G.S. and Notaridou, V.A. (1991) On the meteorological conditions during some strong smoke episodes in Athens. Atmosph. Environ., 25B, 193-202.

Thom, E. (1959) The discomfort index. Weatherwise, 12, 57-60.

Ziomas, I.C., Suppan, P., Rappengluch, B., Balis, D., Tzoumaka, P., Melas, D., Papayannis, A., Fabian, P. and 
Zerefos, C.S. (1995a) A contribution to the study of photochemical smog in the greater Athens area. Beitr. Phys. Atmosph., 68, 198-203.

Ziomas, I.C., Melas, D., Zerefos, C.S., Bais, A.F and Paliatsos, A. (1995b) Forecasting peak pollutant levels using meteorological variables. Atmosph. Environ., 29, 3703-3711.

Ziomas, I.C., Melas, D., Zerefos, C.S., Bais, A.F and Paliatsos, A. (1995c) On the relationship between peak ozone levels and meteorological variables. Fres. Environ. Bul., 4, 53-58.

Ziomas, I.C. (1998a) The mediterranean campaign of photochemical tracers-transport the chemical evolution (MEDCAPHOT-TRACE): an outline. Atmosph. Environ., 32, 2045-2053.

Ziomas, I.C., Tzoumaka, P., Balis, D., Tzoumaka, P., Melas, D., Zerefos, C.S. and Klemm, O. (1998b) Ozone episodes in Athens, Greece. A modelling approach using data from MEDCAPHOT-TRACE. Atmosph. Environ., 32, 2313-2321. 